ÉGYPTE

monde arabe

\section{Égypte/Monde arabe}

\section{5-6 | 2009}

Pratiques du Patrimoine en Égypte et au Soudan

\title{
Les enjeux du patrimoine moderne en Égypte
}

The challenges of modern heritage in Egypt

\section{Galila El Kadi}

\section{OpenEdition}

\section{Journals}

Édition électronique

URL : https://journals.openedition.org/ema/2899

DOI : 10.4000/ema.2899

ISSN : 2090-7273

\section{Éditeur}

CEDEJ - Centre d'études et de documentation économiques juridiques et sociales

\section{Édition imprimée}

Date de publication : 22 décembre 2009

Pagination : 191-220

ISBN : 2-905838-43-4

ISSN : 1110-5097

\section{Référence électronique}

Galila El Kadi, « Les enjeux du patrimoine moderne en Égypte », Égypte/Monde arabe [En ligne], 5-6 |

2009, mis en ligne le 31 décembre 2010, consulté le 07 juillet 2022. URL : http://

journals.openedition.org/ema/2899; DOI : https://doi.org/10.4000/ema.2899 


\section{Galila El KaDi}

\section{RÉSUMÉ / ABSTRACT}

\section{LES ENJEUX DU PATRIMOINE MODERNE EN ÉGYPTE}

L'extension de la notion de patrimoine aux sites et bâtiments de la fin du $\mathrm{XIX}^{\mathrm{e}}$ siècle et au début du XXe siècle en Égypte a généré de nouveaux enjeux culturels, économiques et politiques spécifiques à cette nouvelle catégorie de biens communs. Les divergences d'intérêts et des perceptions qui sous-tendent ces enjeux fragilisent ce processus de patrimonialisation, remettent en question les acquis des quinze dernières années et laissent planer des incertitudes sur son avenir. Cependant, la mobilisation largement médiatisée de l'élite culturelle contre la négligence et les actes de vandalisme amène à sensibiliser de plus en plus l'ensemble de la société tant aux risques encourus par ce legs des temps modernes qu'à ses valeurs tangibles et intangibles. Enjeux patrimoniaux, conflits d'intérêt et sensibilisation sont les thèmes principaux de cet article.

\section{THE CHALLENGES OF MODERN HERITAGE IN EGYPT}

Extending the concept of heritage to sites and buildings from the late $19^{\text {th }}$ and early $20^{\text {th }}$ century in Egypt has raised new cultural, economic and political issues specific to this new category of common property. The conflicting interests and perceptions that underlie these issues undermine the heritagemaking process, questioning the achievements of the last fifteen years and raising uncertainty about its future. However, the widely publicised mobilisation of the cultural elite against neglect and vandalism raises the awareness of increasingly larger segments of society as to the risks incurred by the bequests of modern times in its tangible and intangible values. Economic issues, conflicts of interest and awareness are the main themes of this article. 



\section{Galila El Kadi}

\section{LES ENJEUX DU PATRIMOINE MODERNE EN ÉGYPTE}

$\mathrm{L}$ 'invention d'une nouvelle catégorie de patrimoine n'est pas un acte banal, -qui induit seulement des pratiques de sauvegarde et de valorisation dans un but purement consommatoire. ${ }^{1}$ Au-delà de ces pratiques, cet acte interroge sur les modes de construction identitaires et questionne sur les temporalités nécessaires à I'appropriation symbolique. II engage un rapport à la mémoire collective des lieux, et dans le cas du patrimoine des XIX et $\mathrm{XX}^{\mathrm{e}}$ siècles, questionne aussi sur la relation à la modernité.

Ces questionnements sont au centre des débats en Égypte depuis le séisme qui frappa le pays en 1992 et qui est venu créer l'onde de choc nécessaire à la cristallisation de la mobilisation contre les menaces qui pèsent sur ce legs de l'époque moderne, en vue de sa protection et de sa mise en valeur. Ils révèlent l'importance des enjeux culturels et identitaires générés par la fabrication de ces biens communs. Mais $c^{\prime}$ est sous la pression économique que la question du patrimoine semble se poser de manière ostensible tant elle ne peut être dissociée du marché. La destruction des bâtiments de grandes valeurs, sélectionnés ou classés, témoigne non seulement des approches distinctes de ce patrimoine mais aussi des pressions d'une spéculation massive que celui-ci subit depuis toujours, rendue illégale et intolérable par la législation qui pénalise désormais ce genre de pratiques. Ces enjeux économiques sont accentués par les paradoxes qu'induisent les politiques de sauvegarde et les difficultés de leur mise en œuvre, ce qui révèle les conflits d'intérêts et les logiques divergentes même au sein des instances étatiques gardiennes de la mémoire. Ainsi au cours de ces quinze dernières années on a pu assister à l'extension du processus de patrimonialisation de façon typologique - par inclusion progressive d'objets et de sites d'une grande diversité allant des palais et villas aux parcs et jardins historiques en passant par les bâtiments résidentiels et commerciaux - et géographique, par son élargissement à toutes les villes de province.

1. Sinou, 2005. 
On a constaté aussi l'amélioration des modes de gestion et l'évolution des outils d'appropriation et de valorisation initiés par l'État. ${ }^{2}$ Mais le désengagement de celui-ci face aux actes de vandalisme perpétrés et répétés contre ce patrimoine et son incapacité de faire respecter les lois élaborées par ses propres instances traduisent des alliances suspectes avec des acteurs prompts à bousculer sans aucun scrupule ces "vieilles pierres ». Ces enjeux politiques sont aggravés par le manque d'appréciation général de ce patrimoine par I'ensemble de la société. Tous ces facteurs fragilisent les nouvelles démarches patrimoniales mises en œuvre depuis quinze ans, remettent en question la légitimité des revendications de sa sauvegarde, mettent en péril les acquis et minimisent l'impact des efforts déjà réalisés. Cependant, la formidable mobilisation de l'élite culturelle et politique en faveur de la protection de la mémoire d'une Belle Époque de plus en plus réhabilitée et mythifiée, la large médiatisation des enjeux, des débats, ont considérablement contribué à informer le grand public sur ce qui a été perdu et ce qui est en danger d'être perdu à jamais. Elles ont surtout réussi à les sensibiliser aux valeurs tangibles et intangibles de ce patrimoine ainsi qu'aux nécessités de son maintien et de son traitement avec douceur.

La question principale à laquelle nous tenterons de répondre dans cet article serait de savoir si l'exacerbation de la dialectique destruction/préservation serait à même d'inverser progressivement la donne actuelle en substituant la culture à la spéculation et au vandalisme.

\section{DES LOGIQUES, DES PERCEPTIONS ET DES PRATIQUES DIVERGENTES}

L'observation et l'analyse des différentes pratiques et des perceptions visà-vis du patrimoine moderne en Égypte nous ont amené à cerner les logiques des différents acteurs et à les regrouper schématiquement en quatre groupes principaux: l'élite culturelle, la majorité silencieuse, l'élite économique, les instances étatiques et les collectivités locales.

L'élite culturelle du pays regroupe les hommes de lettres, les architectes et les urbanistes, les archéologues, les historiens et les journalistes ainsi que certaines personnalités politiques. Ce groupe ne représente qu'une infime minorité, qui arrive quand même à faire entendre sa voix et est souvent appuyée par les ONG et les organismes internationaux.

Une grande partie de ces intellectuels se trouve être les seuls à avoir une logique, plus ou moins cohérente et à comprendre les enjeux urbanistiques, économiques, identitaires et culturels. Leur discours en faveur de la

2. El Kadi et El Kerdany, 2005. 
sauvegarde de ce patrimoine repose sur un système de valeurs historiques, symboliques et architecturales universellement reconnues. Ce patrimoine constitue à leurs yeux, des objets rares de la construction humaine et d'inestimables témoignages de l'identité culturelle de la Méditerranée. Les formes urbaines et architecturales produites au cours de la période 1850-1950, ne sont pas perçues par ce groupe, comme dans la majorité des pays du Maghreb, comme étant les "stigmates d'une domination qu'il faut faire disparaître » ${ }^{3}$ mais à l'inverse, les fleurons d'une Belle Époque caractérisée par les métissages culturels et les métamorphoses identitaires, politiques et sociales. Ces expressions architecturale et urbanistique marquent l'entrée de l'Égypte dans la modernité, leur disparition pourrait créer un vide chronologique qui se traduirait par la perte de repères de l'histoire moderne de ce pays. ${ }^{4}$ Celle-ci a laissé son empreinte dans chaque ville; des rues, des places et des monuments, des demeures somptueuses ou de simples bâtiments sont marqués par la mémoire d'un événement, du vécu d’une personnalité remarquable, du passage d'un hôte de marque, ou de la rencontre de gens ordinaires qui ont donné sens à ces lieux par leurs retrouvailles périodiques, leur chaleur et leurs palabres. Histoires connues ou moins connues que I'on veut glorifier ou oublier, constituent la valeur immatérielle des lieux, indissociable de leurs valeurs matérielles, souvent mises en exergue dans la presse par ces intellectuels pour promouvoir la sauvegarde de ce patrimoine ou dénoncer les actes de vandalisme qu'il subit.

Face à ce premier groupe minoritaire, on trouve une majorité silencieuse, totalement indifférente à la sauvegarde de cette nouvelle catégorie de patrimoine, voire même à celle de toutes les autres catégories, tangibles ou intangibles, antiques, médiévales ou plus récentes. Dans ce second groupe d'acteurs, l'enjeu majeur pour les uns est de survivre, pour les autres est de mieux vivre. Les plus pauvres doivent se battre quotidiennement pour obtenir le minimum vital, pouvoir se nourrir, avoir un abri et accéder aux équipements de base. Les moins démunis cherchent à améliorer leur qualité de vie, se procurer un logement décent et assurer l'éducation de leurs enfants. Ces deux sous-groupes, ne vont pas se mobiliser pour défendre des vieilles pierres dont le maintien ou la perte ne changeront rien à leur destin. Les sans abris sont même hostiles à tous les projets de restauration ou de réhabilitation qui impliquent leur déguerpissement.

Les plus nantis, fuient de plus en plus les quartiers modernes construits dans les années 60 pour s'installer loin de la "plèbe » dans des gated communities, aseptisées et hautement gardées. Ces gens-là, sont placés au sommet de la pyramide sociale, ne possèdent paradoxalement pas des ressources culturelles

3. Abdelkafi, 2005.

4. El Kadi et El Kerdany, 2005. 
suffisantes leur permettant d'apprécier les valeurs de leur patrimoine national, de le défendre et moins encore de contribuer à sa sauvegarde. Ils éprouvent la même indifférence vis-à-vis de leur propre patrimoine familial immobilier, qu'ils cèdent volontiers aux plus offrants sans se soucier du destin qui lui est réservé. Par ces pratiques sous-tendues par une logique purement marchande, ils ont indirectement participé, depuis la fin des années 70 aux transformations irrémédiables de l'environnement urbain qui compte de moins en moins de villas trônant dans des parcs verdoyants, mais de plus en plus de tours en béton, en verre et en acier.

En cela, ce sous-groupe rejoint le troisième groupe composé d'hommes d'affaires, de promoteurs immobiliers, ou de simples détenteurs de capitaux issus d'activités souvent illicites. Pour ce groupe, les vieilles pierres sont une entrave à la rentabilité de leurs capitaux. ${ }^{5}$ Les supprimer définitivement leur permet de réaliser des gros profits issus de la rente de situation et du lotissement des grandes parcelles supports de villas ou de petits collectifs en d'autres plus petites en y construisant plus de bâtiments et plus d'étages. Ce groupe qui fait «main basse sur la ville » depuis des décennies, est responsable de la démolition de centaines de villas et de dizaines de palais en milieu urbain et rural dont certaines étaient de grande valeur. L'appétit de ces prédateurs et de leurs alliés régionaux et internationaux n'a pas de limites. Ils convoitent tout autant le patrimoine mineur, urbain et résidentiel, que les sites antiques et médiévaux les plus prestigieux. Ils jouissent de la complicité implicite ou explicite que le quatrième groupe d'acteurs, de loin le plus pesant, celui qui comprend les institutions étatiques et les collectivités locales, leur assure. Les différents acteurs qui composent ce dernier groupe fournissent tous les jours les preuves de l'absence de leur neutralité et de leurs alliances avec le grand capital dont ils défendent les intérêts au détriment de la protection du patrimoine et de celle l'environnement en général. Par conséquent ils jouent de moins en moins le rôle qui leur est dévolu, celui de gardiens du patrimoine et des garants de sa sauvegarde. ${ }^{6}$

Mais les choses sont plus compliquées qu'elles n'apparaissent, cette division en quatre groupes n'est que schématique, de même que les frontières entre ces groupes est très mouvante et aucun groupe n'est exclusif de l'autre. Leur cohésion interne est constamment remise en question et peut provoquer des basculements d'un groupe à un autre. Des alliances se font et se défont, des logiques hier divergentes peuvent se rejoindre demain, tout se passe en fonction des recompositions des intérêts et des tendances, des rapports de

5. Il s'agit du projet de centre financier et touristique du Caire en cours de construction dans le périmètre de sauvegarde de la Citadelle. Cf. Aboukorah, 2007.

6. Ibid. 
force entre les différentes strates, de la nature et de l'envergure des enjeux, et du contexte local et international dans lequel ils s'inscrivent.

Ainsi, la sauvegarde du patrimoine moderne et sa mise en valeur par l'État, répondent-elles au discours international sur les diversités culturelles et vise à améliorer son image de marque en projetant de lui à l'étranger celle d'un État tolérant, favorable aux dialogue des cultures, respectueux de tous les témoignages historiques du passé y compris ceux qui ne font pas partie des sources culturelles " authentiques ». Mais par ailleurs, ce même État, et pour satisfaire les demandes du tourisme international, sacrifie des ressources patrimoniales rares en n'intervenant pas pour empêcher la démolition d'édifices remarquables, et en soutenant des projets qui portent atteinte à des ressources patrimoniales non renouvelables tels que le fleuve et les terres agricoles. Le cas du palais de l'ex-Premier ministre 'Adlî Yakan est révélateur de ce genre de pratiques. Situé dans le quartier chic de Garden City, et conçu en 1914 par Antonio Lasciac ${ }^{7}$, ce palais était le plus somptueux de cette cité jardin du début du siècle. ${ }^{8}$ II formait avec d'autres palais, villas fastueuses et ambassades un admirable front de Nil, véritable Golden Coast $^{9}$ très emblématique de ce quartier et faisant la fierté des Cairotes. Il fut vendu à la fin des années 70 par I'arrière petite fille de cAdlîYYakan à une société suisse d'investissement hôtelier qui comptait le transformer en hôtel. Mais les difficultés financières ont retardé de trente ans cette rénovation désastreuse. Trois décennies au cours desquelles I'État, ou son ministère de la Culture, auraient pu avoir l'occasion de sauver ce bijoux de l'architecture début de siècle, en l'achetant et en l'affectant, à un usage culturel, voire touristique. Abandonné à son sort, il fut rasé dans le plus grand silence au tout début de ce troisième millénaire, et céda la place à une construction ignoble, appartenant à la chaîne hôtelière internationale Four Seasons. Le promoteur, un prince d'Arabie, jeune, moderne et connu pour son mécénat en faveur de la culture, avait projeté, avec l'appui de l'ex-ministre du Logement de l'époque, Ibrahim Soliman - qui est aussi un homme d'affaires d'accaparer le fleuve pour le mettre au service de l'Hôtel. Le projet consistait dans le remblaiement de la branche du Nil passant en partie en face de l'hôtel, sur une longueur de trois kilomètres afin d'aménager une voie sur berge pour y détourner la circulation automobile, d'alléger la pression sur l'axe principal de la corniche ce qui faciliterait I'accès au Four Seasons. Ce projet fut battu en brèche grâce à une forte mobilisation conduite par les architectes et les

7. Antonio Lasciac est un architecte austro-Italien qui fut I'architecte du palais sous cAbbâs Helmî II (1892-1914). Il est l'auteur de nombreux bâtiments remarquables au Caire et à Alexandrie, dont la Banque Misr (1929), symbole du Nationalisme égyptien naissant suite à la révolution de 1919.

8. Raafat, 1998.

9. Abu Lughod, 1971. 
urbanistes, et le ministre a perdu son portefeuille, pour d'autres raisons que son soutien indéfectible à ce projet. ${ }^{10}$

Les mêmes architectes, tous membres de la commission d'architecture, I'une des 24 commissions du Conseil Suprême de la Culture qui se sont soulevés en 2005 contre le projet de la voie sur berge, ont unanimement salué en 2006 l'abrogation de l'ordonnance militaire issue en 1998 par l'ex-Premier ministre Al-Ganzûrî et interdisant la démolition des palais et villas sélectionnés et enregistrés sur les listes des collectivités locales en fonction de critères prédéfinis à l'échelle nationale. ${ }^{11}$ L'application de cette ordonnance aux palais de "valeur exceptionnelle » et aux villas de " grande valeur » allait à l'encontre des intérêts de ces architectes en leur enlevant une part importante de la maîtrise d'ouvrage du marché de la rénovation urbaine. Cette prise de position illustre certes des lacunes conceptuelles, mais aussi des considérations d'ordre idéologique évidentes. Ces architectes restent dans leur grande majorité fascinés par la modernité et se désintéressent des formes architecturales des temps passés qu'elles soient locales ou importées. Leur défense de la propriété privée est liée à leur appartenance sociale, mais en même temps ils ne sont pas tout à fait insensibles aux nouvelles valeurs patrimoniales révélés et défendues par l'élite culturelle à laquelle ils appartiennent. Ces incohérences sont liées comme le constate A. Chastel au fait que

"La dénomination "patrimoine", appliquée aujourd'hui, dans le monde, à des catégories d'objets si diverses, la difficulté de définir à leur égard un comportement censé devient manifeste. La destruction et la ruine de l'inutile est une loi de la nature. La culture intervient pour annuler ou retarder cette loi au nom d'intérêts plus élevés ». ${ }^{12}$

Les exemples qui suivent vont montrer que le processus de patrimonialisation est encore en gestation, ô combien douloureuse!

\section{LA SAGA DES PALAIS ET VILLAS, DESTRUCTION ET REQUALIFICATION}

Le 2 octobre 2007, les habitants du quartier de Umrâniyya, au gouvernorat de Giza, découvrent la disparition totale d'un somptueux palais qui trônait dans un parc d'un demi hectare de superficie et situé à quelques pas du siège du gouvernorat. L'événement ne fait pas la une des médias, il a cependant eu

10. El Kadi 2005a et 2005b. L'auteur de cet article, a fait partie de la commission d'experts qui a réalisé une expertise visant à démontrer l'impact préjudiciable de ce projet à l'environnement urbain et au cours du fleuve lui-même.

11. El Kadi et El Kerdany 2005.

12. Chastel et Babelon, 1994, p. 101. 
droit à trois articles succincts ${ }^{13}$ qui, tout en dénonçant ce vandalisme ont relaté les faits et rappelé les différentes valeurs de cet édifice précieux que l'Égypte venait de perdre. Les lecteurs ont appris avec stupeur que le palais du poète Mahmûd Sâmî Pacha al-Bârûdî (1839-1904) qui vient d'être rasé à même le sol en 48 heures, est inscrit sur la liste des bâtiments de grande valeur historique du Conseil Suprême des Antiquités (CSA) sous le $n^{\circ} 186$. Son titulaire est une des grandes figures de la poésie et de la politique de la fin du XIXe siècle, il fut le compagnon de 'Urâbî, chef de la révolution de 1882, occupa successivement les postes de ministre de la Défense et de premier ministre en 1882, avant d'être exilé la même année par l'administration britannique pendant 18 ans. Mais ni la renommée du "poète du sabre et de la plume » (Shicr al-sayf wal qalâm), ni la valeur historique et architecturale de son palais, n'ont pu intercéder pour empêcher ce massacre. L'auteur du crime est un chauffeur de micro-bus qui acheta le palais aux héritiers du feu poète, pour 20 millions de livres égyptiennes et soudoya deux ingénieurs du gouvernorat de Giza, pour un demi-million de livres. ${ }^{14}$ Cette histoire rappelle étrangement un feuilleton écrit par le dramaturge Usâma Anwar 'Ukâcha et diffusé par la télévision égyptienne au début des années 90. Le personnage central, la mucallima ${ }^{15}$ Faddâ al-Macadâwî, une ancienne poissonnière, incarne bien la nouvelle classe montante de nouveaux riches, incultes, ignorants et arrogants. Elle acheta une somptueuse villa propriété d'un ancien diplomate dans l'objectif de la raser pour construire deux tours à la place. À l'époque, la démolition de la villa de la grande diva égyptienne Um Kulthûm par de nouveaux acquéreurs qui I'ont remplacée par une tour résidentielle de la plus grande laideur, avait suscité beaucoup d'émotions. Cette récente déprédation contre un monument de cette valeur a relancé la polémique sur les enjeux du patrimoine palatial en Égypte.

Éléments les plus vulnérables de l'environnement urbain, les palais et les villas en sont aussi les objets les plus valorisants au vu des valeurs esthétique, historique et symbolique qu'ils recèlent. Par conséquent ils représentent un enjeu majeur de l'urbanisation en général, et de la sauvegarde du patrimoine architectural et urbain en particulier. De tous les temps, dans la majorité des

13. Al-Ahrâm, 3 et 6 octobre 2007, Rûz al Yûsif, 15 octobre 2007.

14. Les journaux n'expliquent pas comment un chauffeur de micro bus peut-il détenir une telle somme. Mais il a probablement agi pour le compte d'un promoteur immobilier.

15. Mucallima, féminin de $m u^{c} a l l i m$, de la racine ${ }^{c} i l m$, savoir, signifie littéralement instructeur ou enseignant. Ce terme est utilisé pour désigner les chefs des corporations des métiers et par extension tout entrepreneur dans les classes populaires qui détient le pouvoir et l'argent. Dans son sens péjoratif, il désigne les costauds et les poissardes. 
pays du monde, les vieux palais de l'aristocratie ont fait l'objet de deux politiques et/ou pratiques contradictoires: destruction totale pour des raisons politico idéologiques suite aux révolutions et au passage d'une monarchie à une république, ou pour des raisons spéculatives ou, à l'inverse, sauvegarde et affectation de nouveaux usages culturels, éducatifs ou diplomatiques. Ces deux politiques alternent, se confrontent, mais peuvent aussi coexister.

En Égypte, les Officiers libres qui ont renversé la monarchie 1952, avaient $d^{\prime}$ autres priorités que la sauvegarde du patrimoine culturel. ${ }^{16}$ Celui-ci fut en quelque sorte mis entre parenthèse jusqu'au début des années 70. Quant aux palais de la famille royale et des grands notables, ils furent rarement perçus comme un patrimoine à sauvegarder. Quelques résidences royales et princières de prestige ont pu être sauvegardées de résidences secondaires ou de lieux d'accueil pour hôtes de marque étrangers ${ }^{17}$, les autres, les plus nombreuses, ont été soit démolies pour des raisons d'aménagement urbain ${ }^{18}$, soit affectées à des fonctions administratives et éducatives, soit défigurées et/ou amputées de leurs parcs verdoyants. ${ }^{19}$

Cette politique a entraîné la disparition, la dégradation irréversible et la ruine d'une multitude de demeures remarquables en Égypte. Les seules qui ont échappé à ce sort furent celles qui ont été achetées par les légations étrangères pour servir de sièges à leur représentation diplomatique. La spéculation foncière, qui s'est généralisée suite à l'instauration en 1973 de la politique

\section{El Kadi, 2004.}

17. Il s'agit du palais de Qubba dans la banlieue est du Caire, et des palais de Muntaza et de Râs al-Tîn à Alexandrie.

18. Les exemples les plus connus sont ceux du palais de Kasr al-Nîl construit par le khédive Ismaïl et utilisé par I'armée Britannique comme Barraquements, remplacé au début des années 50 par le Nile Hilton, et le palais de l'ex-ministre des finances Cattaui Pacha construit en 1920, démoli dans les années 60 pour l'aménagement de la corniche du Nil. (Raafat, 2003, p. 71-72 et p. 83-84).

19. Ce fut le cas du palais du prince ${ }^{C}$ Umar Tûssun aux bords du Canal de Mahmûdiya à Alexandrie. De son vaste jardin botanique de $6000 \mathrm{~m}^{2}$ qui le plaçait tout juste derrière les jardins d'Antoniades à Alexandrie, il ne reste plus que $1000 \mathrm{~m}^{2}$ suite à la construction en 1965 de HLM. Cf. al-Tagamuc, 19 Août 2006. Le titulaire est le petitfils du Khédive Sacîd, un historien et érudit remarquable. Il fut le pionnier des fouilles sous-marines dans la baie d'Alexandrie. La Bibliotheca alexandrina lui a rendu hommage en février 2005 par l'organisation d'un colloque international et la publication de sa biographie. Cf. Al Ahram Hebdo, 30 mars 2005. 
de libéralisation économique, dans un contexte marqué par un vide législatif et institutionnel spécifique, a provoqué encore plus de dégâts. En plus d'un demi-siècle (1952-1993), nul ne peut mesurer ce que l'Égypte a perdu comme joyaux de l'aire libérale. Ce bilan reste à faire, mais on connaît déjà depuis 1993 le bilan de ce qui se perd tous les jours, et ce en dépit de la politique poursuivie par le ministère de la culture depuis le début des années 90.

$C^{\prime}$ est justement à partir de cette date que ce ministère a commencé à faire de la restauration et de la requalification des anciens palais et villas son outil de gestion de la sauvegarde de ce patrimoine. En même temps que le Conseil Suprême des Antiquités (CSA) opérait leur classement sur la liste nationale, ce qui garantissait et renforçait leur protection. ${ }^{20}$ Ainsi de nombreux édifices architecturalement remarquables et historiquement foisonnants d'événements $^{21}$ ont-il été transformés en musées, bibliothèques, hôtels de luxe, ce qui a contribué à doter le Caire et Alexandrie de nouveaux lieux d'échange, de communication, de culture et de loisir. Cette nouvelle politique a permis la contemplation, I'appréciation et l'appropriation de ce patrimoine par un plus grand nombre. Il suffit de visiter le musée de Bayt al-Umma, ex-résidence de Sacd Zaghlûl (1858-1927), chef de la révolution de 1919, de celle du prince des poètes Ahmad Shawkî (1868-1932), ou du doyen des écrivains Taha Husayn (1889-1973), pour se rendre compte de l'impact positif de ce genre d'initiatives sur le public. Contrairement aux grandes demeures royales tels le palais de ${ }^{\mathrm{c}}$ Abdîn, ou celui de Muhammad ${ }^{\mathrm{C}} \mathrm{Alî}$ au nord du Caire à Shubrâ al-Khîma, affectés respectivement à des usages muséographique et culturel, on se sent comme chez soi dans ces villas humbles, mais d'un grand raffinement. Chaque espace restitue le raffinement des goûts, la mémoire sociopolitique et culturelle de l'époque, d'un événement important qui changea le sort de la nation, ou révolutionna les arts et la littérature, ou plus prosaïquement les détails de la vie quotidienne des ces éminentes figures de l'Égypte moderne.

Mais cette politique n'est pas sans faille, elle a des effets pervers. En effet, de nombreux palais et villas récemment classés souffrent de la négligence et de l'abandon par manque de moyens financiers et risquent de rejoindre

20. Gaballah A. Gaballah, Secrétaire général du CSA à l'époque, qui, craignant la démolition du palais de Gîzira, actuel hôtel Marriott suite à l'ajout de deux tours dans son parc, s'empressa de le classer sur la liste des monuments historiques en l'an 2000 (Interview de l'auteur en I'an 2000).

21. El Kadi et Attia, 2002. 
le sort du palais de Samî Pacha Al-Barûdî. ${ }^{22}$ D'un autre côté, la sélection et le classement d'un édifice se révèlent comme une arme à double tranchant. Ces démarches dévoilent les valeurs d'un objet patrimonial ce qui entretient le mythe de sa protection, favorise un changement de regard et facilite de la sorte sa réappropriation. En même temps, elles sont mal perçues par les propriétaires qui y voient une atteinte au libre usage de leurs biens, aiguisent les convoitises des spéculateurs et leurs alliés au sein des collectivités locales et par conséquent exposent l'objet, aux risques de disparition brutale ou de la mort lente. C'est pour cela que l'émission de tout nouveau décret, entraîne plus de démolitions avant la mise en exécution des mécanismes de protection et de pénalisation. Certains fonctionnaires des collectivités locales alliées des propriétaires agissent très rapidement la nuit et pendant les jours fériés pour accomplir leur délit et mettre les instances étatiques devant les faits accom-

22. Les cas des palais du Baron Empain et de celui de Sakâkînî Pacha en sont révélateurs. Le premier a été construit par le Baron Belge Empain au début du siècle lors de la fondation de la cité satellite de Héliopolis à l'est du Caire. Jamais habité, ce palais d'un style indo-européen, qui se dresse à la lisière de la cité au fond d'un grand parc, est l'emblème et de cette banlieue bourgeoise mais aussi un point de repères pour toute la ville. Il fut acheté au début des années 70 de la société de Héliopolis par deux investisseurs arabes, qui avaient l'intention de le démolir pour tirer un meilleur profit d'une localisation exceptionnelle et d'un terrain d'une grande superficie. Se rendant compte des dangers qui menacent cette pièce unique des trésors palatiaux de l'Égypte moderne, le ministère a décidé de l'acquérir. Mais se trouvant incapable de répondre aux exigences des acquéreurs, qui demandaient une somme de 70 millions de L.E., un appel fut lancé à Madame Moubarak pour intervenir personnellement pour sauver le palais. La first lady d'Égypte qui parraine une association de sauvegarde du patrimoine de Héliopolis, est personnellement intervenue auprès du ministère de l'habitat et des nouvelles communautés, qui accepta d'offrir 110 feddans (46,4 ha) aux propriétaires dans la ville satellite du nouveau Caire qui ont une valeur équivalente au prix de vente exigé (informations fournies par A. Kutb, architecte au CSA, mars 2004). Le palais a été sauvé, mais il demeure vulnérable par manque de restauration et d'usage. Le second cas est celui du palais de Sakâkînî Pacha un médecin de grande notoriété très proche du Khédive Ismaïl (1863-1895), il fit construire ce palais dans le quartier de Daher en 1897 dans un style rococo et sa famille le légua à l'État dans les années 60. Le ministère de la santé le géra pendant 30 ans, et voulut en faire un musée de l'histoire de la médecine en Égypte. Dégradé par manque d'entretien, et endommagé après le séisme, il fut classé monument historique en 1997. Les travaux de restauration très onéreuses avancent très lentement. Ils sont interrompus depuis plusieurs années. Comme le palais Empain, celui de Sakâkînî sert de repère aux rats et aux chauves-souris (Al Ahram Hebdo, 3 septembre 2003). 
plis. ${ }^{23}$ Dans les provinces lointaines du $S a^{c} \hat{i} d$ où le patrimoine pharaonique génère des revenus touristiques importants, qui n'ont que peu de retombées sur le développement local du fait de leur accaparement par le pouvoir central, la fabrication d'un nouveau patrimoine ne recueille aucun enthousiasme chez les populations locales et leurs élus.

\section{LES ARCANES DES COLLECTIVITÉS LOCALES}

C'est donc dans les villes provinciales, où le ministère de la culture a étendu sa politique muséale que les enjeux de la sauvegarde semblent être les plus exacerbés. De la ville de Mansoura au cœur du Delta ${ }^{24}$, à Assiout en haute Égypte ${ }^{25}$, les tensions entre les autorités centrales et les collectivités locales à propos du drame des palais historiques alimentent la polémique dans les colonnes de la presse quotidienne. Le cas du palais du Prince Husayn Kamâl situé dans de la ville de $\mathrm{Naga}^{\mathrm{c}}$ Hamâdî au sud de la vallée en est des plus révélateur. L'édifice date de 1910 et fut construit dans un style néo-mauresque. Il est entouré par un parc de 4 feddans ${ }^{26}$, les deux ont été classés respectivement en 1988 et 1989. Le titulaire, né en 1882 est un arrière petitfils de Muhammad ' $A l i ̂$, il a acquis sa notoriété pour son amour des arts, qui se donne à voir dans la collection de peintures qui ornent les murs de ses palais. Mais il s'est surtout distingué par son rôle de mécène en créant les facultés des beaux-arts du Caire et d'Alexandrie. ${ }^{27}$ Commencés en 2003, les travaux de restauration se sont arrêtés suite au refus du conseil local d'octroyer au maître d'ouvrage le permis de reconstruction de l'enceinte suivant son ancien tracé, sous prétexte qu'elle dépassait la nouvelle ligne de redent. Or, le parc entourant le palais est classé périmètre de sauvegarde selon le décret 99 de 1989 et doit rester intact. En dépit de l'injonction adressée par l'ex-Gouverneur de Qena, ${ }^{c} \hat{A} d i l$ Labîb, au conseil local de $\mathrm{Naga}^{c}$ Hamâdî pour faciliter la tâche de I'entrepreneur, I'affaire n'était toujours pas réglée en août 2007. Quatre ans après le début des travaux, le comité technique formé au sein de ce conseil pour étudier le dossier de cette affaire, a reconnu la validité de la propriété du

23. En 2006 à Alexandrie, pendant les deux fêtes du grand et du petit baïram, 20 villas ont été démolies dans le quartier résidentiel de Kafr ${ }^{\mathrm{C}} \mathrm{Abdû}$. Propos du directeur du musée gréco-romain in Al Masrî Al Yawm, 2 août 2006.

24. Le palais de Mohamad Bey El Chenawi (1930), fut classé monument historique en 1999. Il a été légué par les héritiers à l'État et devait être transformé en musée régional (interview avec les héritiers, Mansoura, 2004).

25. Le palais Alexan Pacha à Assiout, construit en 1905, classé monument historique en 1995, est aussi en attente d'être transformé en musée (Al-Wafd, 20 juillet 2007).

26. 1 feddan $=4224 \mathrm{~m}^{2}$.

27. Rûz al-Yûsif, 11 octobre 2007. 
terrain et du palais au CSA. ${ }^{28}$ Les conservateurs du CSA accusent les responsables édilitaires de mauvaise volonté et estiment qu'ils entravent les travaux de restauration dans un but pernicieux. En effet, en temporisant et en bloquant la situation, les fonctionnaires municipaux espèrent enterrer le projet de création d'un musée régional dans le gouvernorat de Qinâ. Or un tel projet aurait eu avoir des retombées positives au rang desquelles figurent la diversification du patrimoine culturel, I'accroissement de l'assise régionale et l'appropriation par la population de sa mémoire récente. Mais un tel projet ne possédait aucune rentabilité économique aux yeux de cette autorité, qui ne voyait dans ce palais qu'un tas de vieilles pierres encombrantes dont l'évacuation assurera un usage plus lucratif du terrain support. La ruine du palais par manque d'entretien sera donc obtenue par la tergiversation et le recours à toutes sortes de blocage bureaucratique par une administration tatillonne. Elle ira de pair avec I'augmentation des coûts de la restauration pour décourager toutes tentatives de récupération. La démolition du palais ou sa vente à un promoteur immobilier pourrait ainsi être réclamée et justifiée, ce qui scellerait définitivement son sort. Ce scénario maléfique est loin d'être une élucubration, ses séquences se sont déroulées sous nos yeux à propos d'un autre cas similaire, celui du palais Sacîd Halîm au Caire.

\section{LE PALAIS SACîD HALÎM²9}

Lorsque le séisme a frappé l'Égypte en 1992, les palais et villas de la fin du XIX ${ }^{\mathrm{e}}$ et du début du XX $\mathrm{X}^{\mathrm{e}}$ siècles constituèrent une des catégories du bâti la plus endommagées. On en dénombra 3000 (sur un total de 11000 édifices altérés), dans leur majorité affectés à des usages éducatifs et gérés par le ministère de l'éducation. ${ }^{30}$ À l'époque, ce fut l'annonce de la démolition de ces demeures par le ministère qui a déclenché la campagne de revendications du legs patrimonial de cette époque et qui a abouti à l'esquisse du cadre

\section{Al Qâhîra, 21 août 2007.}

29. Toutes les informations concernant ce palais sont issues de recherches documentaires et d'interviews auprès des conservateurs du CSA, menées dans le cadre de HERCOMANES, (Heritage Conservation and Management in Egypt and Syria) programme de recherche financée par I'UE dans le cadre du 5 PCRD, il fut lancé en I'an 2000 et s'est achevé en 2003. Ce programme portait sur les centres villes du Caire et d'Alep et avait comme objectif d'améliorer le système de gestion de la sauvegarde des sites et objets de la fin du $19^{\text {e }}$ et du début du $20^{\text {e }}$ siècles dans les deux villes par I'apport de connaissances utiles capables de se transformer en un outil d'aide à la décision. Cette recherche fut coordonnée par G. El Kadi.

30. El Kadi, 1993. 
juridique en faveur de sa protection. ${ }^{31}$ Depuis, les révélations des abus de ce ministère dans le domaine de la gestion et de l'entretien des bâtiments scolaires n'en finissent pas de défrayer la chronique. Or, on ne peut trouver mieux que l'usage éducatif $d^{\prime}$ 'un bâtiment qui possède des valeurs architecturales et historiques remarquables, pour apprendre aux nouvelles générations à apprécier leur patrimoine et à se l'approprier. En Égypte, cet usage a, à l'inverse, entraîné la décadence de l'objet tout en accentuant le rejet et l'oubli. Les anciennes demeures de l'aristocratie furent la proie de toutes sortes d'avanies : démolitions partielles, destructions des éléments décoratifs, transformations inappropriées, ajouts divers, le tout fut aggravé d'une part par le manque total d'entretien et ses effets cumulés pendant plus d'un demi-siècle, et d'autre part, l'augmentation du nombre des étudiants et l'ignorance de leurs enseignants.

Venons-en au palais Sacîd Halîm. Situé rue Champollion au centre ville du Caire, ce palais est la seule demeure royale qui subsiste encore de nos jours au centre moderne fondé en 1865. Sa construction a été ordonnée en 1896 par le prince Sacîd Halîm, fils aîné du prince Muhammad 'Abd al-Halîm, fils de Muhammad 'Alî al-Kabîr. Le palais fut conçu par l'architecte austro-italien Antonio Lasciac dans un style renaissance italienne. Il était entouré par un parc de 2,5 ha bordé à l'ouest par la rue Champollion, à l'est par la rue Husayn Al Micmar, au sud par la rue Antikhana (actuelle Mahmûd Basyûnî) et au nord par la rue Nabarâwî. Les plans de cette époque nous montrent un bâtiment central flanqué de deux ailes latérales qui se prolongent jusqu'à la rue Antikhana. À la fin des années 20, les deux ailes ont été amputées, le jardin réduit, une petite rue constitua désormais la limite sud du palais. Elle le sépara d'un terrain où vit le jour un immeuble de rapport de 6 étages et un grand hangar qui sert à I'heure actuelle de garage et d'atelier de réparation de véhicules.

À la fin de la Première Guerre mondiale, le prince Sacîd Halîm, dernier Premier ministre de la Turquie avant I'avènement d'Atatürk, fut destitué de ses fonctions par les Britanniques, et ses biens furent séquestrés et mis en vente. Le palais, qui n'a jamais été habité, fut vendu en 1918 à un nouvel acquéreur appelé Monsieur Carlsioni qui le loua au ministère de l'Éducation. Celui-ci le transforma en école qui prit le nom Al-Nasrâ, devenue Al Nâsiriya au début des années 40 suite à son rachat par un autre acquéreur nommé Chaoul Mediano. Cet établissement scolaire, fut un des meilleurs de l'époque à l'échelle nationale. Parmi ses anciens élèves on trouve d'éminentes figures de l'élite culturelle du pays tels que : feux ${ }^{\mathrm{c} A l i ̂ ~ e t ~ M u s t a p h a ~ A m i ̂ n, ~ f o n d a t e u r s ~}$ du quotidien Al-Akhbâr, le Dr. Îbrahîm Badrân, ex-ministre de la santé, M. Ismaïl Sirâg al-Dîn, directeur de la Bibliotheca alexandrina, pour ne citer que quelques exemples. L'affectation de cet édifice de $4700 \mathrm{~m}^{2}$ à un usage éducatif,

31. El Kadi et El Kerdany, 2005. 


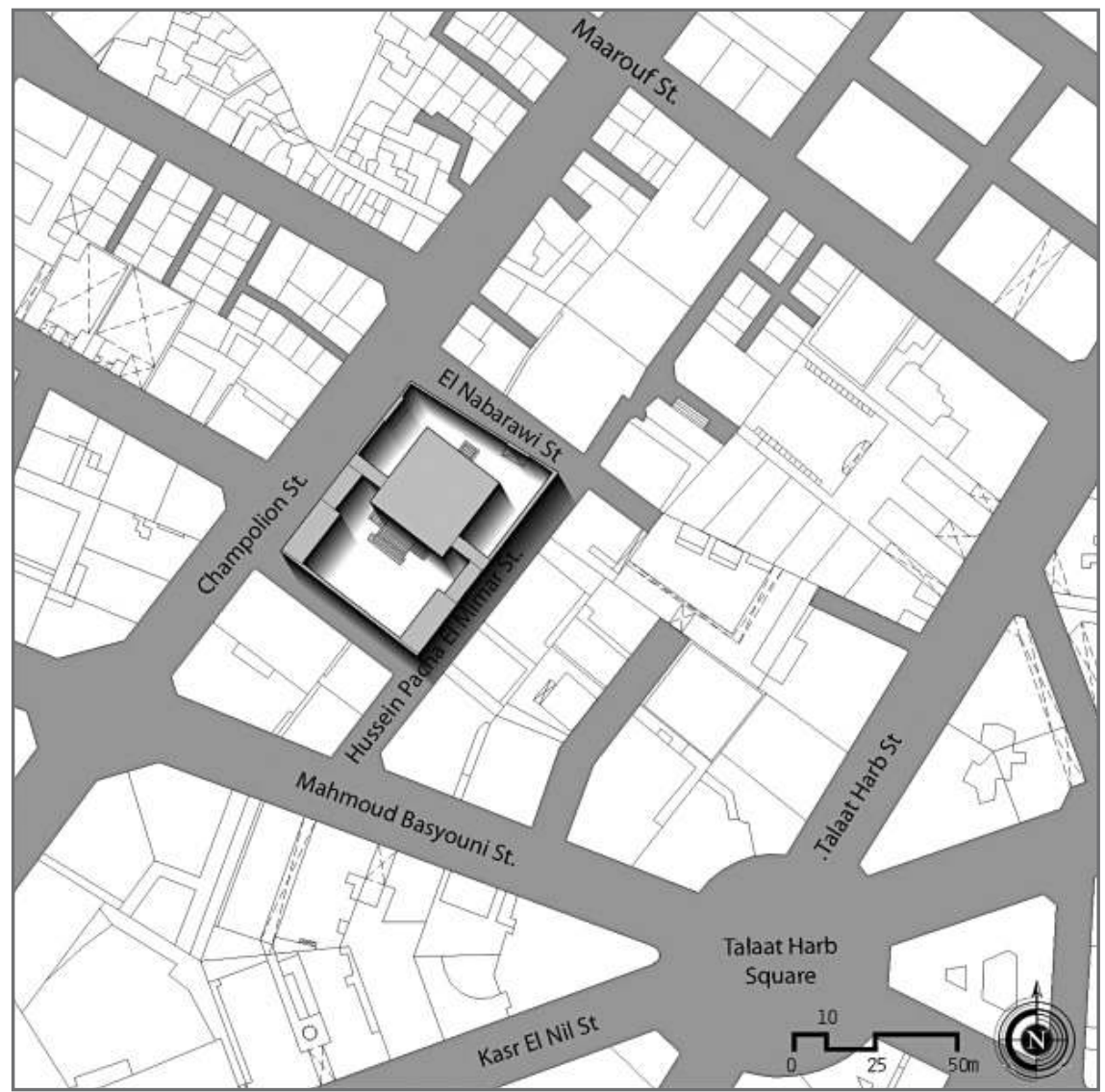

1. Plan de situation du palais (Hercomanes, 2003).

lui a donné un sens et une nouvelle valeur qui ont garanti sa sauvegarde, à une époque où le ministère de l'Éducation s'intitulait ministère du Savoir (Al-Macârif) et avait eu comme ministre, Taha Husayn. À partir de 1952, le déclassement du centre ville, les mutations sociales, le changement des structures et des mentalités, la surpopulation, I'ignorance et la négligence ont eu raison d'une institution autrefois prestigieuse.

En I'an 2000, le palais était dans un état de dégradation avancé et présentait des menaces pour les élèves. Une équipe de recherche composée d'experts internationaux travaillant sur le patrimoine du centre moderne du Caire I'avait identifié comme bâtiment exceptionnel et d'une grande vulnérabilité et a recommandé son classement, sa requalification ainsi que son évacuation. Classé monument historique en I'an 2002 (décret ministériel 121/2002), le palais ne fut pourtant pas évacué en même temps. Il a fallu attendre deux ans, le temps de construire un nouveau bâtiment scolaire dans 


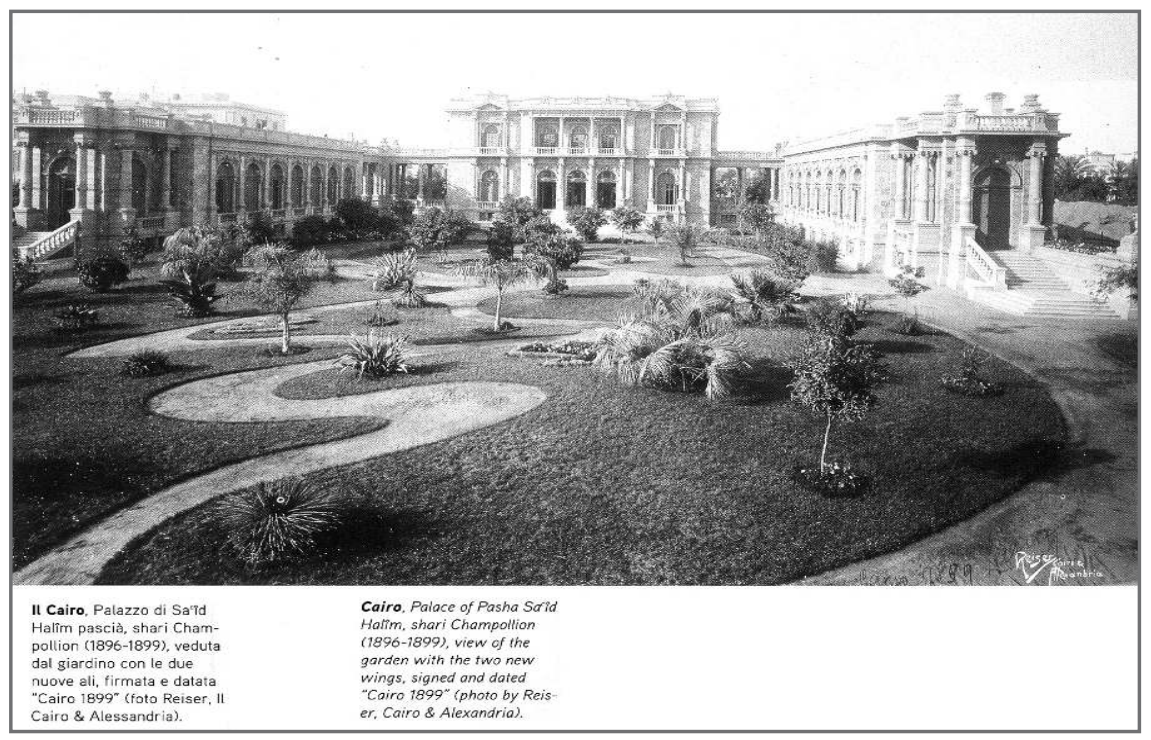

2. Le Palais Sacîd Halîm au début du siècle dernier (Da Gorizia ALL'IMPERO OTTOMANO, Antonio Lasciac Architetto, Alinari, 2006).

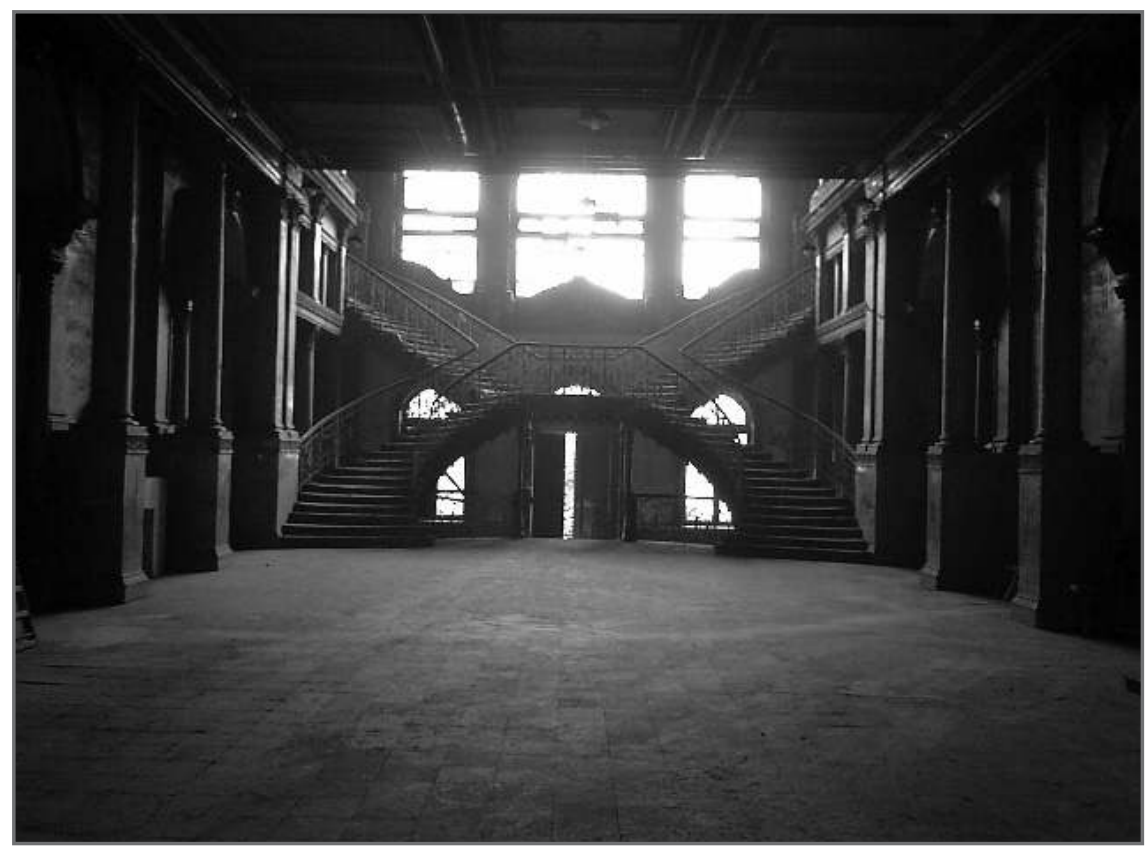

3. Le hall central (Alain Bonnamy). 


\section{West terrace}

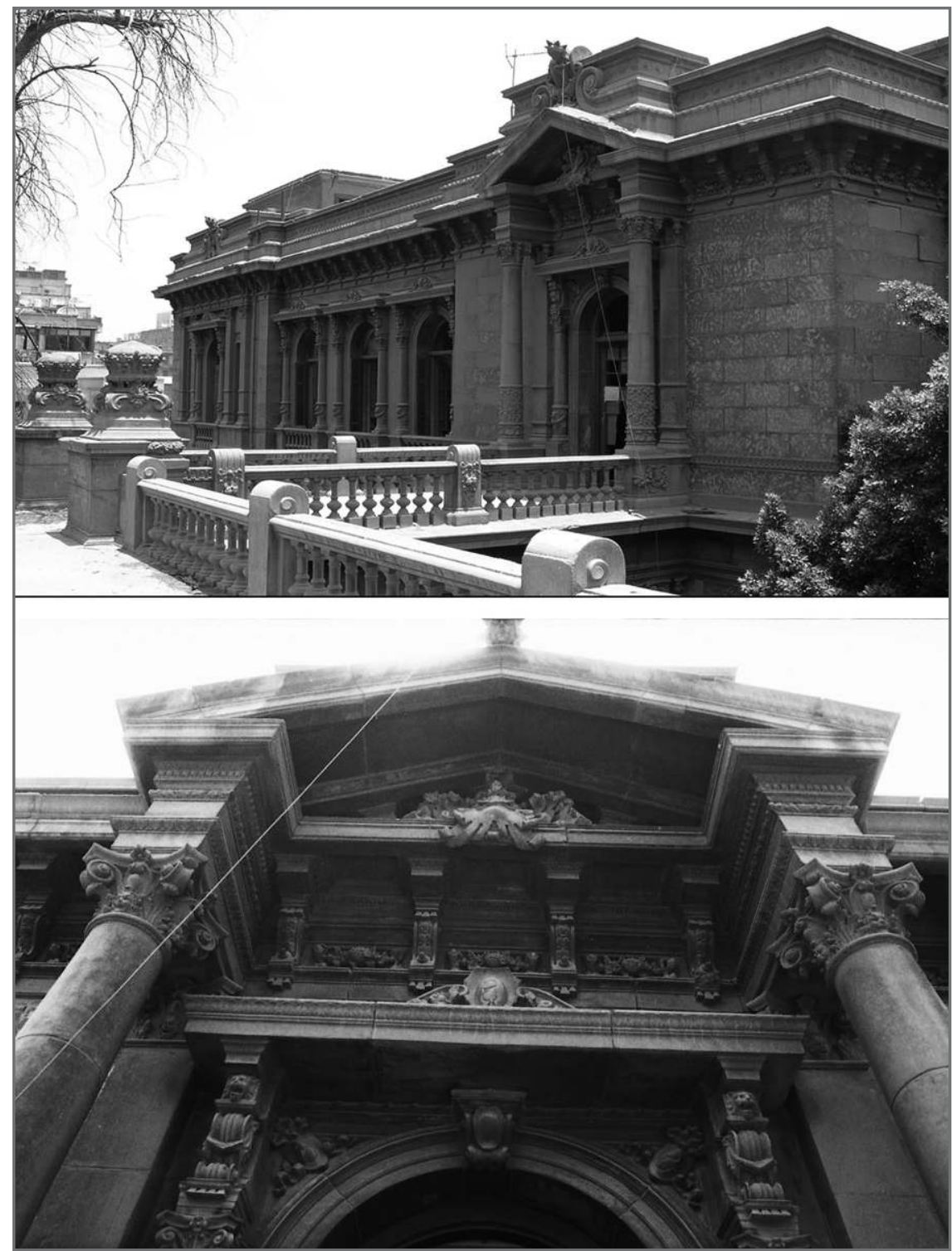

4. Terrasse ouest (Alain Bonnamy). 
le quartier pour accueillir les élèves. En 2004, l'équipe de recherche propose au CSA un projet de transformation du palais en Musée historique de la ville du Caire. L'adoption de ce projet par le CSA s'est heurtée à plusieurs obstacles qui ont mis en lumière des enjeux politiques et économiques considérables, impliquant les ministères de la Culture et de l'éducation et un promoteur immobilier, la société AI Fath. Il s'est avéré que le palais fut acheté à son dernier propriétaire deux mois avant son classement en 2002 par la dite société Al Fath qui a renouvelé le bail de location avec le ministère de l'éducation. On apprend aussi que le président de cette société n'est autre que Rachad Osman, un milliardaire de l'ère de I'Infitah ${ }^{32}$, qui a débuté comme docker au port d'Alexandrie et fit fortune en se lançant dans l'activité d'importation du bois. Très proche du président Sadate, il a été accusé d'exercice d'activités illicites, et fut mis en examen par le tribunal des mœurs suite à la mort du Raïs égyptien en 1981. Pendant longtemps, on n'a plus entendu parler de celui à qui Sadate avait confié la ville d'Alexandrie avant sa mort. ${ }^{33}$ Mais voilà qu'il défraie de nouveau la chronique dans une affaire obscure. Les scandales multiples qui ont éclaté récemment au ministère de la culture ${ }^{34}$ nous amènent à poser plusieurs questions et d'avancer quelques hypothèses. D'abord existent-ils des connivences entre certains fonctionnaires de ce ministère et la société de promotion ?35 Ensuite, le promoteur était-il au courant que le bien qu'il a acheté allait tomber dans le domaine public, et si c'est le cas, qui lui aurait communiqué cette information et dans quel but? Et enfin, pourquoi le ministère de la culture n'a pas fait valoir son droit de préemption pour acquérir un édifice en passe de devenir monument historique lors de sa mise en vente?. Une des premières hypothèses qui se dégage de ces interrogations est que la société comme Al-Fath, ne pouvait pas acheter le palais sans avoir fait une enquête

32. Terme signifiant littéralement ouverture, il désigne la politique de libéralisation adoptée par le pouvoir égyptien à partir de 1973.

33. On se réfère souvent à une histoire vraie devenue une anecdote selon laquelle le président Sadate aurait dit au milliardaire avant sa mort « Fais attention à Alexandrie, ya Rachâd ».

34. Au cours de ces quatre dernières années des proches du ministre de la culture ont été mis en examen pour différentes affaires de corruption. Ont été inculpés par ordre chronologique : le directeur du cabinet du ministre, sa secrétaire, et tout récemment le responsable au sein du ministère de la Culture du Programme National de sauvegarde et de développement du Caire islamique.

35. L'architecte responsable du suivi du projet du musée historique du Caire et qui était notre interlocuteur au sein du CSA, a été mis en examen pour corruption il y a deux mois. Rappelons que la procédure de classement d'un objet sur la liste des monuments historiques suit trois étapes séparées par plusieurs mois: la désignation, la sélection et enfin le classement. Des fuites d'informations permettent aux propriétaires de définir leurs stratégies avant la troisième étape. 
préalable sur son statut et son devenir. Ce qui confirme cette hypothèse, ce sont les pressions qu'elle exerce sur le ministère pour tirer le plus grand profit de cette affaire. D'un côté la société a intenté un procès ( $\left.{ }^{\circ} 38992 / 60\right)$ contre le gouverneur du Caire et le ministre de la culture pour avoir le libre usage de son bien. De l'autre, elle négocie depuis quelques mois la cession de ce bien avec le CSA à un prix exorbitant. Par ailleurs, dans son conflit avec le ministère de la culture et le gouvernorat, la société est soutenue par le ministère de I'éducation. Celui-ci continue à payer le loyer à la société Al-Fath et tergiverse pour la restitution du palais au CSA. Un courrier envoyé par la direction pédagogique du district ouest au promoteur l'alertant de la date fixée par le CSA pour la remise du palais à la commission du ministère de la culture dévoile les alliances entre ces deux partenaires. ${ }^{36}$

En attendant le dénouement de cette affaire confuse, le palais est abandonné à son sort et à son gardien! C'est le seul qui en tire profit en ce moment en louant ses salles aux mécaniciens du coin pour y déposer leurs outils, et son vaste parc aux automobilistes pour y garer leur voiture. ${ }^{37}$ En l'occurrence, les conservateurs du CSA se réfèrent au sort tragique du palais de Habîb Chinûda à Assiout, dont les 395 chambres qui faisaient sa singularité ont servis de poulaillers accélérant sa dégradation et menant à sa démolition, pour mettre en garde le ministère de la culture contre les risques qui menacent les autres palais classés. ${ }^{38}$ Le décalage qui existe entre la capitale et ses provinces dans la mise en œuvre de ce nouveau processus et ses modes de gestion, des temporalités de son appropriation symbolique, accentue davantage la vulnérabilité de ce patrimoine dans les villes secondaires. Les associations métropolitaines

36. Le gouverneur du Caire avait envoyé une lettre au ministère de la culture lui demandant de former une commission pour récupérer le palais. (Sawt al-Umma, $1^{\mathrm{er}}$ octobre 2007).

37. Ibid.

38. Dans une interview à Al Qâhira, organe du ministère de la Culture, Wafaa Saïd responsable des fouilles archéologiques coptes, rappelle que dans le laps de temsp de 14 jours qui s'écoula entre le départ du premier ministre Kamâl Al Ganzûrî et l'en-

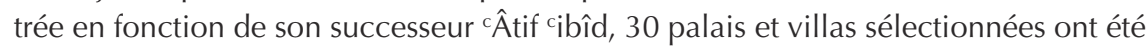
démolies. Elle a souligné l'état de dégradation de tous les monuments classés servant comme établissements scolaires et gérés par le ministère de l'éducation tels que : le palais de 'Umar Tûssun à Shûbra (319/1984), le portail de Sulaymân 'Abdû au Lycée français de Macâdi (115/1993), le palais du roi Fouad à Kafr Al Chaykh (1490/1992), le palais de la princesse Ferial à Tanta $(617 / 99)$... La liste comprend trente palais répartis sur l'ensemble des gouvernorats. (Al Qâhira, 8 septembre 2007). 


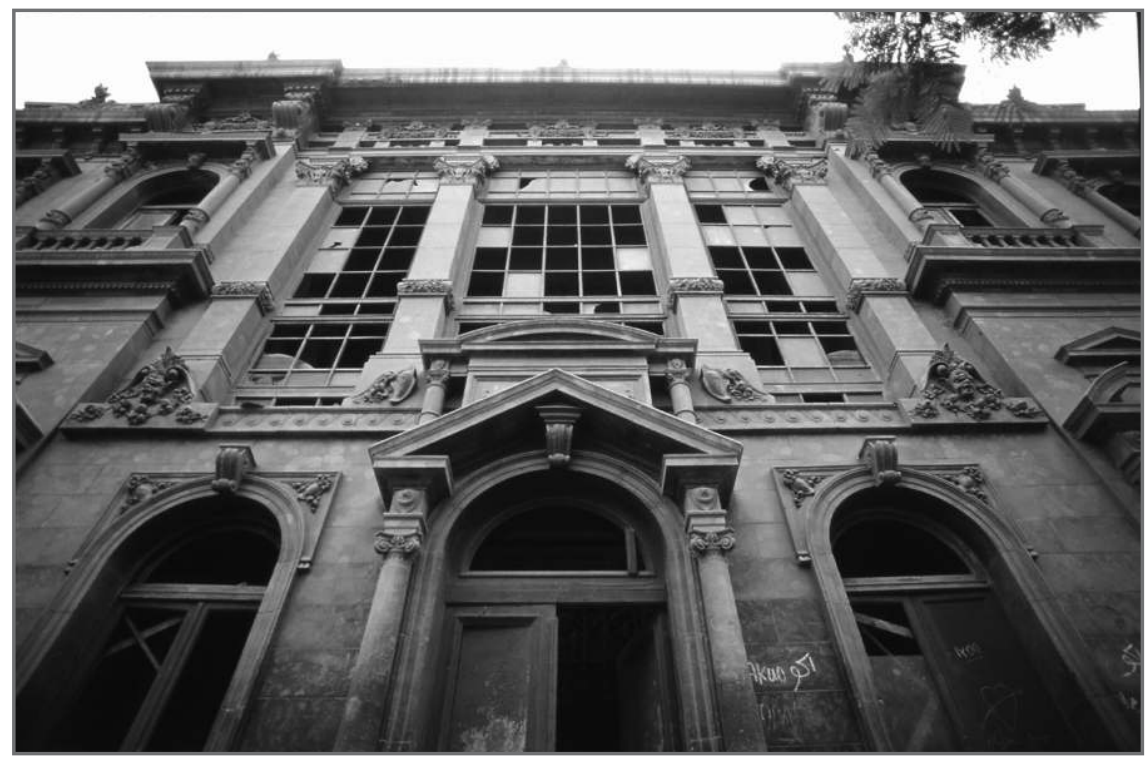

5. Façade Nord (Alain Bonnamy).

de sauvegarde au Caire ${ }^{39}$ et à Alexandrie s'intéressent rarement à ce qui se passe hors de ces deux capitales. Mais la médiatisation des faits et la large circulation des informations seraient à même de créer des solidarités et des synergies dans ce domaine et générer une mobilisation nationale. C'est ce qui se construit depuis quelques mois dans I'affaire du projet de transfert du campus universitaire d'Alexandrie.

\section{LA BATAILLE D'ALEXANDRIE}

"Contrairement à Beyrouth, Alexandrie n'a pas eu besoin d'une guerre civile pour voir sa physionomie à jamais transformée, sa structure et sa vie sociales entièrement remodelées, son ambiance de cité cosmopo-

39. L'association de sauvegarde des amis de l'école Nâsiriya fut créée en 2007 pour défendre le palais Sacîd Halîm et sa transformation en Musée de l'histoire du Caire. Elle regroupe 45 adhérents, anciens diplômés encore vivants. Si pour le moment, les efforts de l'association se centrent sur la défense du projet du musée dans le palais Sacîd Halîm, elle projette de d'étendre son activité à tous les palais de l'Égypte moderne. 
lite remplacée par une atmosphère marquée par les origines rurales de ses nouveaux habitants. Au bord de la Méditerranée, sur un immense front de mer, dorment les traces encore vivantes d'une Andalousie perdue, dont le lustre s'est éteint au milieu du XXe siècle ».40

C'est par cette phrase qu'un journaliste d'al-Mustagbal commence un long article sur la seconde métropole égyptienne, qui de symbole du cosmopolitisme est devenue une ville provinciale banale, qui perd tous les jours sa personnalité architecturale n'offrant à ses visiteurs que quelques vestiges éparses qui évoquent un rêve lointain. Si les années 50 ont sonné le glas du métissage de sa population, au cours des cinq décennies suivantes l'alliance entre la corruption bureaucratique et l'affairisme ont eu raison de son cachet le plus spécifique, ce front de mer, représentant le dialogue visuel entre les cultures. Des tours hideuses, constituant une longue barrière qui sépara la ville de sa mer, sont venues remplacer, les anciens immeubles harmonieux fin du siècle et art nouveau. Les restaurants, les cafés, les bars, qui se succédaient le long d'une corniche transformée en autoroute ont fermé leur porte tour à tour. Au début du troisième millénaire, son patrimoine palatial et résidentiel vole en éclat à un rythme hallucinant. ${ }^{41} \mathrm{Or}, \mathrm{c}^{\prime}$ est avec l'avènement de ce siècle que l'État avec l'aide internationale reconstruit la Bibliothèque d'Alexandrie, opération d'une portée culturelle et symbolique qui vise à faire renaître la vieille cité cosmopolite de ses cendres. Mais si ce nouveau joyau de l'architecture moderne prêche le dialogue entre les cultures et se fait le chantre de la sauvegarde de ses manifestations tangibles et intangibles, le hiatus entre les discours et les pratiques se creuse de jour en jour. De phare culturel, la Bibliotheca est devenu le chantre de la privatisation. Relatons la chronologie des faits.

Cela remonte à 1994 lorsqu'on a confié à une commission d'experts égyptiens l'évaluation du projet lauréat de la Bibliotheca alexandrina. Les experts ont unanimement adopté ce projet sous réserve d'aménager les abords de cet édifice de prestige. Or, pour cela, il fallait démolir l'hôpital pédiatrique de Shatbî qui sert en même temps de centre hospitalier universitaire ainsi que quatre immeubles attenants. Le scénario final prévit la démolition de la partie la plus vétuste de ce $\mathrm{CHU}$, la restauration et le maintien du reste, moins pour la valeur patrimoniale du bâtiment que pour les fonctions qu'il remplit et qui rayonnent à l'échelle régionale. En effet cet édifice de cinq étages vieux d'un demi-siècle, accueille 100000 patients par an et 500 étudiants par jour, comme il reçoit les cas urgents de tous les gouvernorats limitrophe. En 2005,

\section{Bazi, 2004.}

41. Trente villas ont été démolies dans le quartier résidentiel de standing Kafr ${ }^{\mathrm{C}} \mathrm{Abdû}$ entre 2003 et 2006, selon A. ' ${ }^{\text {Abd }}$ al-Fatâh conservateur en chef des musées et des antiquités d'Alexandrie in Al-MasriAl-Yawm, 10 octobre 2006. 
cinq ans après I'inauguration de la Bibliotheca, la démolition du CHU est de nouveau à l'ordre du jour. La vieille bâtisse et ses usagers semblent porter préjudice à l'élégant monument du troisième millénaire et altèrent son image de marque. Un hôtel cinq étoiles qui accueillera les visiteurs, en nombre croissant de ce haut lieu de la culture, semblait être plus digne de son voisinage. Ce projet était soutenu, voire réclamée par le directeur de la Bibliotheca et I'ex-Gouverneur d'Alexandrie, Al Mahgûb. Mais la substitution du tourisme à la santé et à l'éducation souleva un large mouvement de protestation inattendu dans les milieux universitaires tant à Alexandrie qu'au Caire, surtout lorsqu'on sait, qu'aucune autre construction n'était projetée pour remplacer celle que l'on comptait démolir. Le projet fut temporairement gelé. Ses adeptes n'ont jamais mentionné l'enjeu que représente le site occupé par l'hôpital, mais justifiaient toujours la démolition par le mauvais état du bâtiment dont la structure a été affaiblie par le séisme de 1992. On peut donc se demander, comme disent les détracteurs du projet, pourquoi a-t-on dépensé un demimillion de livres égyptiennes pour le restaurer si on avait l'intention de le démolir?

Deux ans après, en 2007, avec I'arrivée d'un nouveau Gouverneur, 'Âdil Labîb, la question de la destruction du CHU resurgit, mais cette fois-ci, elle $s^{\prime}$ inscrivait dans un projet d'urbanisme plus important dont elle ne représentait que l'option la moins désastreuse pour cette ville et son patrimoine architectural et urbain. Ce nouveau projet consistait au transfert de l'Université d'Alexandrie sur un autre site situé à l'extérieur de la ville, de démolir les bâtiments qui forment le campus universitaire actuel, de vendre les terrains aux capitaux arabes et internationaux et d'affecter les 12 milliards de L.E. tirés de cette vente au financement de la construction de la nouvelle université (4 milliards de L.E.), et à la création d'un nouveau centre moderne qui rivaliserait avec ceux des pays du Golfe, Dubaï et Abû Dhabi. Il se basait sur les arguments suivants :

- La création de l'Université d'Alexandrie ne se fonde pas sur un plan d'urbanisme, mais sur l'adaptation d'anciennes villas et palais aux usages éducatifs. De ce fait, elle ne forme pas un campus homogène et se trouve être éclatée sur 25 sites, ce qui bloque toute tentative de modernisation de I'enseignement ;

- Les bâtiments existants sont vétustes dans leur majorité, certains d'entre eux sont totalement irrécupérables tel le bâtiment de la faculté de Médecine dentaire, ils n'ont par ailleurs aucune valeur patrimoniale, car aucun n'a été classé par la commission du CSA, par conséquent, rien n'empêche donc leur démolition ${ }^{42}$;

42. Le point de vue du responsable secteur ouest du CSA (Akhbâr Al-Adab, 11 mars 2007). 
- La vente des terrains des sites de l'Université apportera 12 milliards de L.E. Dont le quart pourrait être affecté à la construction d'un nouveau campus. Commentant ces thèses, I'économiste Galâl Amîn s'est indigné en rappelant que

" dans les années 70, la privatisation signifiait la substitution du secteur privé, considéré comme étant plus efficace, au secteur public [...] Ce qui se passe maintenant $c^{\prime}$ est la vente des capitaux fixes de l'état au capital international [...] Tout le monde se souvient de la tentative de cession ou de vente du plateau des pyramides par le président Sadate à une entreprise de Hong Kong qui prévoyait d'y aménager des terrains de golf $» .{ }^{43}$

G. Amîn conclut sur le fait que l'affaire de I'Université d'Alexandrie s'inscrit " dans la même logique de tout brader » Le plus choquant à ses yeux est que

« dans cette affaire l'initiative n'est pas celle d'un promoteur mais du directeur de l'Université, du ministre de l'enseignement supérieur et du gouverneur de la ville $»{ }^{44}$

Un des professeurs de l'Université d'Alexandrie, hostile comme l'ensemble du corps enseignant à ce projet abonde dans le même sens en accusant le pouvoir d'avoir vendu « tout le secteur public » aux capitaux internationaux, et aussi

« I'histoire, la géographie et tout ce qui est cher aux gens, dans un contexte de manque de transparence et de suspicions qui entourent ce genre de transactions de grande envergure... Aucune valeur patrimoniale ne trouve grâce à leurs yeux, ils lui substituent cyniquement les valeurs marchandes $»{ }^{45}$

La politisation du débat montre à l'évidence que les enjeux en cours quel que soit l'objet, le périmètre de sauvegarde $d^{\prime}$ une des merveilles du monde, ou les bâtiments de grande valeur de l'Université d'Alexandrie - sont surtout d'ordre économique et politique. Par conséquent, la polémique qui s'est déclenchée depuis quelques mois dans tous les médias a dépassé une approche centrée sur le patrimoine pour embrasser d'autres dimensions touchant à l'aménagement et à la gestion intégrés de l'urbain, aux stratégies de développement territorial, aux choix opérés et à leur priorité. Les débats passionnants qui ont opposé les détracteurs et les supporters de ce projet ont mobilisé de nombreux acteurs : des professeurs d'université, des ministres, des conservateurs du patrimoine, des architectes et des urbanistes, des chercheurs,

43. In Al-Dustûr, 23 avril 2007.

44. Ibid.

45. Al-Sibâcî in Akhbâr al-Adab, 11 mars 2007. 
des responsables des collectivités locales, des journalistes de renom. Ils ont révélé l'existence de deux logiques fondamentalement antinomiques et inconciliables : la logique culturaliste, rationnelle et scientifique des détracteurs du projet, la logique ultra-libérale, marchande et pragmatique ses supporters. Les premiers dénoncent d'abord l'absence totale d'un plan d'aménagement global qui intégrerait tous les problèmes identifiés : la vétusté des bâtiments du campus universitaire, la valeur patrimoniale de certains d'entre eux, la valeur symbolique et historique du site de l'Université pour la ville et ses habitants, les surdensités dues à l'augmentation du nombre des étudiants, la nature du nouveau site prévu pour l'extension du campus universitaire. Ensuite, celle d'une étude d'impact évaluant les coûts socio-économique, démographique, culturel et urbain d'une opération de cette envergure. Ils soulignent enfin les lacunes démocratiques du système, la décision de la vente des terrains du campus ayant été prise par le conseil de l'Université qui regroupe 25 membres sur les 6000 membres du corps enseignant, aucune concertation n'a eu lieu. Si tout le monde s'accorde sur l'existence de problèmes réels de fonctionnement de la ville, leurs solutions ne doivent pas se faire au détriment du patrimoine. Celui-ci est représenté par : les bâtiments de la faculté Polytechnique construits en 1949 dans un style néo-pharaonique, de la faculté des Sciences, de style victorien et du siège de I'Université, à l'origine un hôpital conçu dans un style gréco-romain par l'architecte italien Jiacomo Loria. Ces bâtiments ont été désignés comme bâtiments de grande valeur par une commission d'experts rattachée au gouvernorat d'Alexandrie et sont par conséquent protégés par la loi 144 de 2006 et "personne ne pourra y toucher sans prendre l'avis de la commission $»{ }^{46}$

$C^{\prime}$ est ce qu'a déclaré $M$. ' Awad, professeur et président de la commission d'inventaire, et directeur du centre de recherche sur la Méditerranée à la Bibliotheca alexandrina, avant d'ajouter

« Nous sommes certes favorables à l'extension de l'Université, mais les

solutions contre les surdensités ne doivent pas se faire au détriment de

I'histoire ${ }^{4}{ }^{47}$

$\mathrm{Ni}$ au détriment de l'esprit et de la mémoire des lieux, et des points de repère qui ont marqué au fil des temps l'imaginaire collectif et auxquels les habitants sont attachés, comme l'exprime Mahmûd ' $A b d$ al-Fadîl, professeur d'économie à l'Université du Caire, en ces termes

"J'imagine mal le quartier de Chatbî sans université et le jardin des chalâlat sans étudiants ${ }^{4}{ }^{48}$

46. 'Awad in Akhbâr Al-Adab, 11 mars 2007.

47. Ibid.

48. In Al-Musawar, 23 mars 2007. 
Non plus aux dépens des fonctions de la centralité car

"La démolition du complexe des sciences humaines qui se trouve au centre d'Alexandrie exclura une des fonctions importantes de la centralité urbaine de cette ville $»{ }^{49}$

Et moins encore des terres agricoles puisque le terrain sélectionné par les autorités pour les besoins de transfert de l'Université est un

« terrain agricole de 500 feddans (250 ha), mis à la disposition de la Faculté d'agronomie et affectés aux recherches en agronomie ». ${ }^{50}$

Le front de contestation qui s'est soudé contre ce projet ne s'est pas contenté de critiquer, il a fait des propositions concrètes. Estimant d'abord que la construction d'un nouveau campus ne constituait pas une priorité, dans un contexte de décadence de l'enseignement et de la médiocrité des salaires des enseignants, il a esquissé des alternatives à court et moyen terme qui pourraient contribuer à alléger les pressions sur l'Université d'Alexandrie qui joue un rôle régional. Les traits généraux se résument comme suit :

- Le renforcement du rôle de I'université du Gouvernorat limitrophe de Damanhûr ;

- Le maintien du campus actuel avec la restauration des bâtiments dont les coûts ne représentent que le $1 / 8^{\text {e }}$ des coûts de la création du nouveau campus ;

- L'élaboration d'un plan de restauration des bâtiments et qui pourrait s'étaler sur cinq ans à raison de 100 millions de livres par an. ${ }^{51}$

Cette forte mobilisation soutenue par le mouvement du 8 mars de l'Université du Caire qui milite pour l'indépendance des universités et l'amélioration de l'enseignement, a amené les supporters de ce projet à réviser leur position. Ainsi, au cours d'une émission télévisée où furent invités le ministre de l'Enseignement supérieur et le président de l'Université d'Alexandrie, tous deux ont démenti toute intention de toucher aux bâtiments de grande valeur dont on réclamait la sauvegarde. Pour le reste, le débat reste ouvert, la bataille n'est pas encore terminée.

\section{CONCLUSION}

Les quinze ans qui se sont écoulés entre 1993, date de l'émission du premier décret de protection du patrimoine moderne ${ }^{52}$, et 2008, ont été jalonnées

49. Al Sibậ̂ in Akhbâr al-Adab, 11 mars 2007.

50. Ibid.

51. M. 'Abd al-Fadîl in Al Musawar, 23 mars 2007.

52. Décret 300 de 1993 interdisant la démolition des palais et villas de grande valeur. 
par des grands moments de revendications, de sensibilisations, d'appropriations et de valorisations. Nous nous référons surtout à la campagne lancée par un comité parrainé au plus haut niveau par Madame Suzanne Moubarak pour la sauvegarde de la mémoire des temps modernes ${ }^{53}$, au $9^{\text {e }}$ colloque de I'association des architectes sur le patrimoine qui eut lieu en 1999, et où, pour la première fois, plusieurs cessions ont été consacrées aux nouveaux modes de gestion des sites et bâtiments produits à la fin du XIXe et au début du XX $X^{\mathrm{e}}$ siècles $^{54}$; à la restauration du palais de la princesse Samîha à Zamâlek, devenu Bibliothèque du Grand Caire ${ }^{55}$; à l'inauguration du palais de Muhammad ' $A l i ̂$ à Chubrâ et sa transformation en lieu de rencontres culturelles ${ }^{56}$; à la sortie du film L'immeuble Yacoubian faisant suite à la publication de l'ouvrage du même nom ${ }^{57}$; aux festivités et cérémonies organisées en plusieurs lieux à I'occasion du centenaire de la banlieue est de Héliopolis en 2006 et enfin à l'émission, au cours de la même année, d'une loi cadre qui organise la protection de l'ensemble de ces sites et objets. En quinze ans, I'histoire récente de l'Égypte a été revisitée, réécrite, réinterprétée, et réhabilitée et restituée au grand public dans des séries télévisées transmises par les antennes satellitaires aux spectateurs du Maghreb et du Machrek, en plein mois de Ramadan, ce qui a énormément bouleversé les idées reçues sur l'ère de la monarchie. ${ }^{58}$

53. Ce comité regroupait la commission Fulbright, I'agence gouvernementale de la Bibliothèque Moubarak et Al-Ahram Weekly.

54. Patrimoine architectural et développement urbain, le Caire 18-19 avril 1999.

55. La construction de ce palais a été commandée par la famille Cattaui au début du siècle passé quand elle se déplaça du centre ville pour élire résidence dans l'île de Zamâlek. Il a été acheté par la princesse Samîha fille du Sultan Husayn Kamâl qui gouverna l'Égypte entre 1914 et 1917 . Celle-ci le légua à l'État égyptien avant sa mort. La bibliothèque qui s'y installa fut inaugurée en 1995. Adolphe Aslan Cattawî est un financier égyptien de confession juive éminent qui joua un rôle important dans la vie politique égyptienne au début du XXe siècle.

56. Ce palais fut construit entre 1808 et 1821 et conçu par I'architecte français Pascal Coste dans un style éclectique mélangeant le rococo et des connotations arabisantes. Il fut inauguré en 2006 par le président Moubarak après une restauration qui dura sept ans.

57. Le roman de 'Alâ' Al Aswânî, 'Imârit Yackûbiân, publié pour la première fois en arabe en 2002 par les éditions Merit a eu un succès international et a été traduit dans de nombreuses langues. C'est le premier roman égyptien où les événements se déroulent au centre ville moderne du Caire. Le film du même nom, réalisé par Marawân Hâmid, a été projeté en 2006 dans plusieurs capitales européennes et fut très bien accueilli par le public.

58. Cf. El Kadi et El Kerdany, 2005. Le dernier feuilleton de cette série portait sur l'époque du Roi Farûq, dernier roi d'Égypte. Il a été diffusé au cours du mois de ramadan dernier qui tombait en novembre 2007. 
L'allégorie d'une Belle Époque de métamorphoses identitaires, démocratiques et culturelles a ainsi remplacé l'image d'une époque marquée par la corruption, le libertinage et la lutte entre les partis de l'opposition. En quinze ans nos connaissances se sont considérablement améliorées grâce à la publication et à l'organisation de colloques et d'expositions photographiques, de la publication et la diffusion d'ouvrages scientifiques, d'études, d'articles destinés au grand public, et de catalogues de photos $^{59}$, des revues de vulgarisation et de la création de sites web spécifiques. ${ }^{60}$ Toutes ces actions ont permis d'établir les liens nécessaires entre la population et son histoire, provoqué une mutation des regards, ont éveillé les consciences et invité à la réflexion, à la contemplation, à l'appréciation et ont créé les conditions favorables à la défense de ce patrimoine par les habitants eux-mêmes. Mais en même temps, tous ces acquis sont fragilisés par les divergences des intérêts, des logiques et des perceptions accentuées par l'ignorance, l'indifférence, la pauvreté et un désir démoniaque de destruction de tout ce qui est beau, tout ce qui donne sens à la mémoire collective. Ces facteurs remettent en question le nouveau processus et interrogent son avenir. Toutefois, la mobilisation largement médiatisée des débats sur le patrimoine en général et sur sa composante moderne, constitue un garde-fou contre tout retour en arrière d'une part, et contribue d'autre part, à franchir chaque jour un pas vers la construction d'un consensus général autour du sens attribué à la mémoire et aux objectifs de sa sauvegarde. Il y a juste quinze ans, toutes les destructions et atteintes à ce patrimoine pouvaient avoir lieu dans le plus grand silence. La médiatisation de tous les événements, festifs ou désastreux, des combats et les débats, des pénalisations et des laisser faire, a fait du patrimoine un lieu de débat démocratique, suscité une opinion publique et généré un processus participatif. De nombreux combats en faveur de la sauvegarde de ce patrimoine furent ainsi gagnés contre I'alliance de I'argent et de I'ignorance. ${ }^{61}$ Le dernier en date est celui du garage de la place Ramsès : un parking de 6 étages construit sur une des plus grandes places de la capitale, qui de surplus dissimulait la gare centrale, un monument de style néo-mauresque construit au milieu du XIXe siècle. La campagne de contestation menée dans les médias par Samir Gharîb, le directeur du nouvel

59. Cf. El Kadi et El Kerdany, 2005. L'ouvrage très imagé de Cyntia Mynti, Paris Along the Nile, vient d'être traduit en arabe par le Conseil Suprême de la Culture.

60. Nous nous référons surtout à la revue Misr Al-Mahrûsa et au site web de Samîr Ra'fat www. Egy.com.

61. On pense à la bataille gagnée par les habitants de Zamâlek au début des années 90 contre la démolition de I'ambassade de Hollande (El Kadi et El Kerdany, 2005), à la victoire remportée par les architectes et les urbanistes dans I'affaire des berges du Nil, au triomphe acquis par le front élargi des acteurs dans la bataille d'Alexandrie... 
organisme d'harmonie urbaine contre cette bâtisse qui défigurait une place, objet de toutes les convoitises, a porté ses fruits et le garage a été démoli. ${ }^{62}$ Simultanément, le front des défenseurs du patrimoine moderne attire de nouveaux adhérents, qui appartenaient hier seulement à la majorité silencieuse. Nous avons appris que les membres du très snob Guézirah Club de l'île de Zamâlek, ont lancé une pétition contre la démolition d'une vieille halle où se déroulèrent de nombreuses compétitions sportives, qui restent gravées dans les mémoires, pour être remplacée par un bâtiment plus haut, mais sûrement plus laid et surtout sans aucune mémoire. ${ }^{63}$ Nous avons été agréablement surpris par campagne de collecte de dons lancée par le ministre de la Culture et le secrétaire général du CSA au peuple égyptien dans son ensemble et aux hommes d'affaires en particulier pour financer la construction du nouveau musée d'égyptologie. ${ }^{64} C^{\prime}$ est le développement de ce processus participatif et ses déclinaisons à tous les niveaux de la prise de décision, du financement, de la réhabilitation, de la redistribution des bénéfices en vue d'assurer l'accessibilité et la jouissance du plus grand nombre aux sites du patrimoine qui pourraient consolider les acquis et substituer progressivement la culture à la spéculation.

\section{RÉFÉRENCES BIBLIOGRAPHIQUES}

AbDelKAfI J. 2005 «Patrimoine culturel et identités de la Méditerranée contemporaine », communication présentée au Colloque ISMARMED, Alexandrie, mars 2005.

AвOukORAh O., 2007 "Un Caire chaque jour un peu plus historique, une institution patrimoniale chaque jour un peu moins garante du patrimoine », en, Chroniques égyptiennes, Enriques Klaus et Chaymaa Hassabo (dirs.),Le Caire, CEDEJ, p. 240-273.

Aвu Lughod J., 1971, Cairo, 1001 years of City Victorious, Princeton, Princeton University Press.

AkHBÂr AL-AdAB, 1997, Wast Al-Balad, numéro spécial, n² 28, 6 avril 1997.

Babelon J-P., Chastel A., 1994, La notion de patrimoine, Paris, Liana Levi.

62. Cf. Akhbâr al-Yawm, 21 juillet 2007, 10 novembre 2007 et 2 février 2008. C'est sur décision du Premier ministre que la démolition du garage a été ordonnée en 2008.

63. L'auteur de cet article a signé cette pétition qui a circulé sur le net en janvier 2008.

64. Dans son appel incantatoire aux égyptiens, le ministre de la Culture a demandé aux Égyptiens de donner une livre égyptienne chacun (0,8 euros) (Al-Wafd, 18 juillet 2007). 
Bazı Y., 2004, "Retour dans une ville mythique », in Courrier International, $n^{\circ}$ 720, 19 Août 2004.

El Kadi G., Attia, S. (dir.), 2002, "Restoring Cairo », Masr al Mahrûsa, volume XVII, Le Caire, février 2002.

El KadI G., El Kerdany D., 2005, «Valorisation pat rimoniale en cours de la ville moderne du Caire », in El Kadi G. et al., Inventer le patrimoine moderne dans les villes du Sud, Autrepart, 33, juin 2005, p. 89-108.

El KADI G., 1993, «Le Tremblement de Terre en Égypte » in Égypte/ Monde Arabe, 14, Le Caire, $2^{\mathrm{e}}$ trimestre, p.134 -163.

- 2004, "La genèse du patrimoine en Égypte : du monument au centre historique » in Gravari-Barbas, M. et Guichard-Angis, S. (dir.), Regards croisés sur le patrimoine dans le monde à l'aube du XXle siècle, Paris, Presses de I'Université de Paris-Sorbonne, p. 99-115.

- 2005a, "Le vol du fleuve » (Ikhtitâf al Nîl) (en arabe) in Al-MasriAl Yawm, 8 janvier 2005.

- 2005b, «De Titi au Four Seasons »(min titi lil Four Seasons) (en arabe), Akhbâr al Adab, 20 février 2005.

Sinou A., 2005, «Enjeux culturels et politiques de la mise en patrimoine des espaces patrimoniaux » in EL KADI, G. et al., Inventer le patrimoine moderne dans les villes du Sud, Autrepart, 33, juin 2005, p.13-32.

RaAfat S., 1998, "Garden City, a retrospective, part I ", site web www.egy. com, 6 août1998.

- 2003, "Cairo the glory years », Harpocrates, Le Caire. 